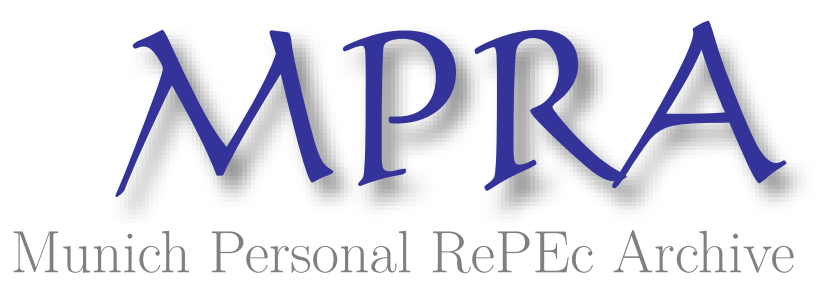

\title{
Individual Welfare and the Demand for Financial Instruments
}

Jehle, Geoffrey

Vassar College

July 1984

Online at https://mpra.ub.uni-muenchen.de/73410/

MPRA Paper No. 73410, posted 03 Sep 2016 14:49 UTC 
Individual Welfare and the Demand for Financial Instruments Author(s): Geoffrey A. Jehle

Source: Southern Economic Journal, Vol. 51, No. 1 (Jul., 1984), pp. 116-134

Published by: Southern Economic Association

Stable URL: http://www.jstor.org/stable/1058326

Accessed: 29-08-2016 16:43 UTC

JSTOR is a not-for-profit service that helps scholars, researchers, and students discover, use, and build upon a wide range of content in a trusted digital archive. We use information technology and tools to increase productivity and facilitate new forms of scholarship. For more information about JSTOR, please contact support@jstor.org.

Your use of the JSTOR archive indicates your acceptance of the Terms \& Conditions of Use, available at http://about.jstor.org/terms

Southern Economic Association is collaborating with JSTOR to digitize, preserve and extend access to Southern Economic Journal 


\title{
Individual Welfare and the Demand for Financial Instruments*
}

\author{
GEOFFREY A. JEHLE \\ Vassar College \\ Poughkeepsie, N. Y.
}

\section{Introduction}

A great deal of attention has been focused in recent years on the theory and practicability of partial equilibrium welfare analysis in markets for ordinary goods and services. This research has resulted in a better understanding of the theoretical relationship between product prices, incomes, and individual and social welfare, and in the specification of rigorous methodologies for theoretical and empirical analysis of the welfare aspects of policies affecting prices, market structures, and the availability of products.

The markets for financial instruments, specifically the markets for credit and debt, have so far escaped careful scrutiny and have not benefitted equally from these advances in welfare theory. For certain purposes, it may be useful and proper to treat the markets for credit and debt as exactly analogous to ordinary goods and services markets. However, for the purposes of individual and social welfare analysis these markets deserve separate consideration. Agents' behavior in the markets for credit and debt reflect and largely summarize their intertemporal allocations of resources between ordinary goods and services markets in different time periods. Since welfare analysis of this market behavior must build upon the underlying structure of individuals' decision-making, and since this decisionmaking explicitly involves the dimension of time, the welfare analysis must also explicitly recognize and account for the role of time.

What little attention welfare analysis of credit and debt markets has received, either directly or indirectly, has been largely confined to the banking literature where such problems as the relationship of interest rates on borrowing and lending to individual and social welfare are of obvious relevance to issues of banking regulation and banking market structure analysis. Typified in papers by Rhoades [9], Benston [1], and Policano [7], this work has been mostly empirical and has relied heavily on tenuous analogies drawn between ordinary markets and the markets for financial instruments. These analogies have been fundamentally ad hoc, and have been offered without explicit theoretical justification.

This paper provides a solution to this problem which is both theoretically justifiable

*This work is taken from the author's doctoral dissertation at Princeton University. I am grateful to Stephen Goldfeld, Dwight Jaffee, and Robert Willig for their advice and criticism. They bear no responsibility for any remaining errors. 
and empirically useable. In section II, individuals' demands for financial instruments are derived from a generalized Fisherian intertemporal consumption model. These demands are expressed in terms of the future value of the borrowing and lending undertaken by the individual in the initial period of an arbitrary time horizon, and are dependent on their current period prices or discount rates. In section III an exact measure of the influence of these prices on individual welfare is constructed, observable surplus measures are defined which are analogous to ordinary consumer surplus, and the relationship of these observable surplus measures to the theoretically exact measure is specified. It is shown that with proper adaptation and interpretation, the entire spirit and substance of Willig's $[11 ; 12]$ well-known solution to the problem of estimating individual welfare in ordinary markets can be carried over to the particular type of intertemporal decision-making which gives rise to market demands for financial instruments. Section IV illustrates how the observable surplus measures can be calculated from the usual interest rate and present value form which demands for financial instruments commonly take in theoretical and empirical work. Contrary to what appears to be generally presumed, the proper observable surplus measures which bear a clear and definite relationship to accepted theoretical measures of individual and social welfare are not properly calculated as simple areas under observable demands for financial instruments. However, it is shown that simple adaptations in the calculation of those areas suffice to enable definite and precise welfare calculations to be made. The final section illustrates how the theoretical methods constructed in the paper can be applied to calculate the welfare costs of bank mergers. Results of simple statistical tests challenge the conventional wisdom associating mergers that cause large increases in market concentration with large welfare losses to bank customers.

\section{The Model of Individual Behavior}

Individuals are assumed to possess a $T+1$ period planning horizon over which they are currently prepared to make financing decisions. They are assumed to possess a preference ordering over commodities in the $T+1$ periods with the necessary properties to permit its representation at fixed commodity prices by a utility function $U\left(C_{0}, C_{1}, \ldots, C_{T}\right)$ that is continuous, twice-differentiable, strictly increasing, and strictly quasiconcave in consumption levels $C_{k}, k=0, \ldots, T$. The individual is endowed with initial wealth $w$ and expects future incomes $y_{1}, \ldots, y_{T}$ with certainty. Consumers are assumed to have access to an array of financial instruments with which to finance their intertemporal consumption plans which they contract for in the initial period. These instruments are partitioned into two groups: those that constitute obligations of the consumer to pay $\$ 1$ in some future period, and those that represent the obligations of others to pay the consumer $\$ 1$ in some future period. The former group, which will be called "loans," and the latter group called "deposits," are available in maturities of from one to $T$ periods. Let $L_{k} \geq 0, k=1, \ldots, T$, be the total number of obligations to deliver $\$ 1$ at the beginning of period $k$ which the consumer sells, and let $D_{k} \geq 0, k=1, \ldots, T$, be the total number of obligations to receive $\$ 1$ at the beginning of period $k$ which the consumer buys.

It is clear that if the individual contracts for any of these obligations it will affect the amount of funds a vailable for $k$ th period consumption. Any $D_{k}$ held, representing promises to receive funds, will increase consumption possibilities in period $k$ and any $L_{k}$ held, 
representing promises to pay funds, will reduce them. For each future period total consumption will be ${ }^{1}$

$$
C_{k}=y_{k}+D_{k}-L_{k} \quad k=1, \ldots, T .
$$

The consumer must take future incomes $y_{k}$ as given, but can affect current and future consumption levels by purchases and sales of deposit and loan contracts in the current period.

The utility function defined over consumption levels $C_{k}$, which will not be realized until future periods, may be transformed into one defined over current period consumption plus a commitment in the current period to a financing plan that will achieve the desired consumption plan. A modified version of the conventional Fisherian framework is obtained by substituting (1) into the utility function and writing it as

$$
U\left(C_{0}, y_{1}+D_{1}-L_{1}, \ldots, y_{T}+D_{T}-L_{T}\right) .
$$

Any particular financing plan will affect $C_{0}$, the level of current period consumption, in a way that will be described in detail below. For now, however, it is sufficient to simply recognize the properties of the utility function as it is written in (2) by noting that the strict quasiconcavity of the utility function in the $C_{k}$, together with the linearity of (1), guarantee the strict quasiconcavity of (2) in $C_{0}$, the $D_{k}$ and the $L_{k}$. In effect, this substitution allows the intertemporal consumption problem to be reduced to a problem of choosing the current period consumption and "savings" levels, and of allocating that savings to credit and debt instruments. ${ }^{2}$

Individuals face fixed current period prices $p_{k}$ at which they sell their obligations $L_{k}$, and fixed current period prices $d_{k}$ at which they buy others' obligations $D_{k}$. These prices are equivalent to "discount rates" calculated from effective single-period interest rates or yields applicable over the term of the credit or debt contract. If $r_{k}$ and $\delta_{k}$ are the effective single-period interest rates on loan and deposit contracts of term $k$, respectively, then $p_{k}=$ $1 /\left(1+r_{k}\right)^{k}$ and $d_{k}=1 /\left(1+\delta_{k}\right)^{k}$. Since $0 \leq r_{k}<\infty$ and $0 \leq \delta_{k}<\infty, 0<p_{k} \leq 1$ and $0<$ $d_{k} \leq 1$. $^{3}$

In the current period, the individual maximizes utility by choosing a level of current period consumption $C_{0}$ and an optimal combination of purchases and sales of the $D_{k}$ and $L_{k}$ to finance the (implicit) intertemporal consumption plan. That choice is constrained by the requirement that current period consumption, plus net expenditure on financial instruments of all maturities, not exceed initial wealth. Total outlays for deposit instruments of maturity $k$ are $d_{k} D_{k}$, and receipts for loan instruments of maturity $k$ sold are $p_{k} L_{k}$. Net current period expenditure on financial instruments of all maturities is the sum over all maturities of the difference between what is paid for the purchase of deposit contracts and what is received from the sale of loan contracts. In the current period, therefore, the individual must choose the level of current consumption and a financing plan whose present value does not exceed initial wealth:

1. The consumption level achievable in any future period will also be affected by borrowing or lending undertaken in periods prior to the current one. This can be easily allowed for but will be ignored here for simplicity.

2. The general structure of (2) is, in principle, similar to that of Morishima [6], but is less restrictive since it does not require the assumption of separability of the utility function between consumption and financing variables.

3. Any loan or deposit, regardless of the particular payment terms, may be thought to consist of the current sale or purchase of several instruments as they are defined here, at different "long rates" $\delta_{k}$ or $r_{k}$. See Hicks [3, 145]. 


$$
C_{o}+\sum_{k=1}^{T}\left[d_{k} D_{k}-p_{k} L_{k}\right]=w .
$$

The individual's problem is to choose non-negative values of $C_{0}, D_{k}$ and $L_{k}$ to maximize (2), subject to (3). Under the assumptions about the utility function a solution to this problem exists and is unique. ${ }^{4}$ It is worth emphasizing that even though the decision problem is cast in terms of actions taken in the current period alone, the individual is not constrained to make simple allocations of funds between the current and various future periods. By appropriate purchases and sales of financial instruments in the current period, intertemporal transfer of funds between any two arbitrary periods within the planning horizon can be achieved.

Straightforward analogues to the usual indirect utility function and expenditure function can be defined which will be useful in the welfare analysis to come. Letting $\mathbf{p} \equiv\left(p_{1}, \ldots, p_{T}\right), \mathbf{d} \equiv\left(d_{1}, \ldots, d_{T}\right), \mathbf{D} \equiv\left(D_{1}, \ldots, D_{k}\right), \mathbf{L} \equiv\left(L_{1}, \ldots, L_{k}\right)$, and suppressing the parameters $y_{k}$, the indirect utility function is defined as

$$
\begin{aligned}
v(\mathbf{p}, \mathbf{d}, w) \equiv \max & U\left(C_{o}, D_{1}-L_{1}, \ldots, D_{T}-L_{T}\right) \\
\text { s.t. } \quad & C_{o}+\mathbf{d} \cdot \mathbf{D}-\mathbf{p} \cdot \mathbf{L}=w ; \\
& C_{o} \geq 0, L_{k} \geq 0, D_{k} \geq 0 \quad k=1, \ldots, T .
\end{aligned}
$$

The expenditure function, defined as the minimum "expenditure," or wealth, which is necessary in order to achieve a given level of utility when facing a set of prices and future incomes, is given by

$$
\begin{aligned}
e(\mathbf{p}, \mathbf{d}, v) \equiv \min & C_{o}+\mathbf{d} \cdot \mathbf{D}-\mathbf{p} \cdot \mathbf{L} \\
\text { s.t. } & U\left(C_{o}, D_{1}-L_{1}, \ldots, D_{T}-L_{T}\right)=v \\
& C_{o} \geq 0, D_{k} \geq 0, L_{k} \geq 0, \quad k=1, \ldots, T .
\end{aligned}
$$

By definition, the indirect utility function and expenditure function are related by the familiar identity:

$$
e(\mathbf{p}, \mathbf{d}, v(\mathbf{p}, \mathbf{d}, w)) \equiv w .
$$

Some useful characteristics of individual demand behavior may be derived from these two functions. Application of the envelope theorem to (4) establishes the following derivative property of the indirect utility function. ${ }^{5}$

$$
\begin{aligned}
& -\left(\partial v / \partial p_{k}\right) /(\partial v / \partial w)=-L_{k}(\mathbf{p}, \mathbf{d}, w) \leq 0 \\
& -\left(\partial v / \partial d_{k}\right) /(\partial v / \partial w)=D_{k}(\mathbf{p}, \mathbf{d}, w) \geq 0 \quad k=1, \ldots, T .
\end{aligned}
$$

Note that the right-hand sides of (7), which depend on loan and deposit prices and wealth,

4. Non-negativity restrictions and the linearity of the constraint equation in (3) guarantee that the constraint set is closed, bounded, and therefore compact. The continuity of $U(\cdot)$ assures that a solution exists. The convexity of the constraint set beneath this boundary, together with the strict quasiconcavity of the objective function, guarantee that the solution is unique.

5. These derivatives exist and are well-defined as long as the consumer is not locally satiated and is at an interior solution in the $C_{k}, k=0, \ldots, T$. 
are the (signed) "Fisherian" demands for loan and deposit obligations, analogous to the Marshallian demands for ordinary goods and services. It is crucial to notice, however, that these derivatives give the Fisherian demands for loan and deposit contracts in terms of their future values, rather than their present values.

Similar application of the envelope theorem to (5) shows that the price partial derivatives of the expenditure function give the (signed) Hicksian, or utility-constant, demands.

$$
\begin{aligned}
& \partial e / \partial p_{k}=-L_{k}(\mathbf{p}, \mathbf{d}, v) \leq 0 \\
& \partial e / \partial d_{k}=D_{k}(\mathbf{p}, \mathbf{d}, v) \geq 0 \quad k=1, \ldots, T .
\end{aligned}
$$

It is easy to show that $e(\mathbf{p}, \mathbf{d}, v)$ is concave in prices and monotonic increasing in $v$. Concavity in prices, together with (8), establish that the own-substitution effects of deposit and loan price changes have the expected signs. ${ }^{6}$

\section{Individual Welfare and Observable Surplus}

In this section an exact measure of the effects of deposit and loan price changes on individual welfare will be constructed. This measure will generally be unobservable. However, observable measures can be specified that will approximate the theoretically correct measure to a high degree of accuracy. Borrower and depositor surplus concepts, analogous to ordinary consumer surplus, will be used for this purpose. When these surplus measures are properly defined, and only when so defined, arguments exactly parallel to those of Willig $[11 ; 12]$ can be used to establish a clear relationship between observable surpluses and rigorous notions of individual welfare under a wide range of circumstances encountered in theory and practice.

The fundamental tool for the analysis of individual welfare is the wealth-compensation function, $\mu$ ( $\left.\mathbf{p}, \mathbf{d} \mid \mathbf{p}^{0}, \mathbf{d}^{0}, w^{0}\right)$, defined as the minimum current period wealth necessary at prices ( $\mathbf{p}, \mathbf{d})$ to make the consumer just as well-off as at some base prices and wealth, $\left(\mathbf{p}^{0}\right.$, $\mathbf{d}^{0}$ ) and $w^{0}$. Implicitly, the wealth-compensation function is defined as

$$
v\left(\mathbf{p}, \mathbf{d}, \mu\left(\mathbf{p}, \mathbf{d} \mid \mathbf{p}^{0}, \mathbf{d}^{0}, w^{0}\right)\right) \equiv v\left(\mathbf{p}^{0}, \mathbf{d}^{0}, w^{0}\right)=v^{0} .
$$

An important property of the wealth-compensation function may be seen by differentiating (9) with respect to prices $p_{k}$ and $d_{k}$, and using (7):

$$
\begin{aligned}
& \partial \mu / \partial p_{k}=-\left(\partial v / \partial p_{k}\right) /(\partial v / \partial w)=-L_{k}(\mathbf{p}, \mathbf{d}, \mu) \leq 0 \\
& \partial \mu / \partial d_{k}=-\left(\partial v / \partial d_{k}\right) /(\partial v / \partial w)=D_{k}(\mathbf{p}, \mathbf{d}, \mu) \geq 0 \quad k=1, \ldots, T
\end{aligned}
$$

where $\mu \equiv \mu\left(\mathbf{p}, \mathbf{d} \mid \mathbf{p}^{0}, \mathbf{d}^{0}, w^{0}\right)$. The right-hand sides of (10) are, respectively, the Hicksian demands for $L_{k}$ and $D_{k}$, both relative to utility level $v^{0}$.

In modern welfare theory, the "compensating variation" [3] is widely accepted as a proper measure of the effect on consumer welfare of an ordinary commodity price change.

6. That is, an increase in $p_{k}$ (decrease in interest rate $r_{k}$ ) causes a substitution in favor of $L_{k}$ along a given indifference curve, and an increase in $d_{k}$ (decrease in deposit rate $\delta_{k}$ ) causes a substitution out of $D_{k}$ along a given indifference curve.

7. There are, of course, many other such measures. However, the Hicksian compensating and equivalent variation are the most common. For brevity, the analysis here will focus on the compensating variation alone, though all important results can be derived in terms of the equivalent variation as well. 
An analogous compensating variation in wealth, $C V$, may be defined here as the wealth adjustment which is necessary after a loan or deposit price change in order to leave the consumer just as well off as under the base situation. $C V$ is defined implicitly as

$$
v\left(\mathbf{p}, \mathbf{d}, w^{0}+C V\right) \equiv v\left(\mathbf{p}^{0}, \mathbf{d}^{0}, w^{0}\right) \text {. }
$$

The compensating variation and the wealth-compensation function are very closely related. In particular, $w^{0}+C V=\mu\left(\mathbf{p}, \mathbf{d} \mid \mathbf{p}^{0}, \mathbf{d}^{0}, w^{0}\right)$ and, of course $w^{0}=\mu\left(\mathbf{p}^{0}, \mathbf{d}^{0} \mid \mathbf{p}^{0}, \mathbf{d}^{0}, w^{0}\right)$. Noting the dependence of $C V$ on the two sets of prices,

$$
C V\left(\mathbf{p}, \mathbf{d} \mid \mathbf{p}^{0}, \mathbf{d}^{0}, w^{0}\right)=\mu\left(\mathbf{p}, \mathbf{d} \mid \mathbf{p}^{0}, \mathbf{d}^{0}, w^{0}\right)-\mu\left(\mathbf{p}^{0}, \mathbf{d}^{0} \mid \mathbf{p}^{0}, \mathbf{d}^{0}, w^{0}\right) .
$$

In view of (10), $C V$ can be represented by a path-independent line integral of the gradient of the wealth-compensation function or, simply, as areas under the Hicksian demands for financial instruments. Using the relationshp of $\mu(\cdot)$ to $C V$ and an important theorem in welfare economics, the consumer's indirect utility function may be written in terms of $C V$ and the consumer's wealth. This theorem, originally due to Hurwicz and Uzawa [4, 119] and recalled by Willig [11, 53], shows that a demand-generating indirect utility function like $v(\cdot)$, derived from an ordinary utility function possessing the quasiconcavity and differentiability properties assumed in the second section above, is transformable by a strictly monotone increasing function into another demand-generating indirect utility function defined in terms of the wealth compensation function. Their findings are recalled here as Proposition 1.

Proposition 1. For $v(\cdot)$ as in (4) and $\mu(\cdot)$ as in (9), there exists a strictly monotone increasing function which transforms the individual's indirect utility function into an equivalent indirect utility function defined in terms of the wealth-compensation function. In particular, for arbitrary but fixed prices $(\tilde{\mathbf{p}}, \tilde{\mathbf{d}})$, the indirect utility function may take the form

$$
\tilde{v}=\mu(\tilde{\mathbf{p}} \tilde{\mathbf{d}} \mid \mathbf{p}, \mathbf{d} w) .
$$

Proof. Let $(\tilde{\mathbf{p}}, \tilde{\mathbf{d}})$ be an arbitrarily chosen set of fixed prices. Given any set of prices (p, d) and wealth $w$, there exists some level of wealth which enables the individual to achieve the same level of utility facing $(\tilde{\mathbf{p}}, \tilde{\mathbf{d}})$ as achieved facing $(\mathbf{p}, \mathbf{d})$ and having wealth $w$. Formally, there exists some $\tilde{\mu}$ such that

$$
v(\tilde{\mathbf{p}}, \tilde{\mathbf{d}}, \tilde{\mu}) \equiv v(\mathbf{p}, \mathbf{d}, w)
$$

where, $\mu^{\sim} \equiv \mu(\tilde{\mathbf{p}}, \tilde{\mathbf{d}} \mathbf{p}, \mathbf{d}, w)$. Recalling the definition of the expenditure function, invoking (6), and using (P.1), it is clear that $e(\tilde{\mathbf{p}}, \tilde{\mathbf{d}}, v(\mathbf{p}, \mathbf{d}, w) \equiv e(\tilde{\mathbf{p}}, \tilde{\mathbf{d}}, v(\tilde{\mathbf{p}}, \tilde{\mathbf{d}}, \tilde{\mu})) \equiv \tilde{\mu}$. Substituting for $\tilde{\mu}$ gives

$$
e(\tilde{\mathbf{p}}, \tilde{\mathbf{d}}, v(\mathbf{p}, \mathbf{d}, w)) \equiv \mu(\tilde{\mathbf{p}}, \tilde{\mathbf{d}} \mid \mathbf{p}, \mathbf{d}, w) .
$$

Since $(\tilde{\mathbf{p}}, \tilde{\mathbf{d}})$ are fixed, (P.2) is simply a specific function of (p,d) and $w$. By the monotonicity of $e(\cdot)$ in $v$, the l.h.s. of (P.2) is simply a monotonic transform of the indirect utility function $v(\cdot)$. As such, $\mu(\tilde{\mathbf{p}}, \tilde{\mathbf{d}} \mid \mathbf{p}, \mathbf{d}, w)$ preserves all of the ordinal properties of the individual's preferences captured by $v(\mathbf{p}, \mathbf{d}, w)$ and so may itself serve as an indirect utility function. ${ }^{8}$ The statement of the theorem follows directly. Q.E.D.

8. The function $\mu(\tilde{\mathbf{p}}, \tilde{\mathbf{d}} \mid \mathbf{p}, \mathbf{d}, w)$, of course, possesses all of the demand-generating properties that $v(\mathbf{p}, \mathbf{d}, w)$ does. To verify this, differentiate the l.h.s. of (P.2) with respect to any price and wealth, then use (7). 
This proposition constitutes a major step towards observability and measurability of consumer's welfare by permitting the ordinary indirect utility function, which gives an ordinal index of consumer welfare measured in unobservable and incomensurate "utils," to be transformed into an equivalent ordinal index of consumer welfare measured in observable "dollar," or wealth units. A strict corollary to this proposition, originally noted by Willig $[11,53]$ for the case of ordinary commodity price changes, follows directly from the definition of $C V$ in (11) and provides another important step towards observability.

Corollary. At any set of prices and wealth the indirect utility function can be represented by a dollar-scaled index consisting of the sum of wealth and the compensating variation in wealth from the given prices to any arbitrary set of prices. In particular,

$$
\tilde{v}=C V(\tilde{\mathbf{p}}, \tilde{\mathbf{d}} \mid \mathbf{p}, \mathbf{d}, w)+w .
$$

Proof. Since $\mu(\mathbf{p}, \mathbf{d} \mid \mathbf{p}, \mathbf{d}, w) \equiv w$, the indirect utility function in Proposition 1 can be rewritten as

$$
\tilde{v}=[\mu(\tilde{\mathbf{p}}, \tilde{\mathbf{d}} \mid \mathbf{p}, \mathbf{d}, w)-\mu(\mathbf{p}, \mathbf{d} \mid \mathbf{p}, \mathbf{d}, w)]+w .
$$

By (11) the term in brackets is the compensating variation in wealth from $(\mathbf{p}, \mathbf{d})$ to $(\tilde{\mathbf{p}}, \tilde{\mathbf{d}})$. Q.E.D.

The form of the indirect utility function given above provides a tool measured in observable units which can be used to directly analyze the effects on individual welfare of loan price changes, deposit price changes, and wealth changes. While it is defined in observable units, the level of this index of individual welfare cannot be directly observed. This is because $C V$, though an exact measure of the welfare effect of price changes, is not directly observable since it represents areas under Hicksian demands which are themselves not observable. A final link between $C V$ and something that is observable is needed. That link can be established by direct analogy in the current intertemporal setting to Willig's well-known solution to the problem of estimating the compensating variation in income using a sequence of areas under ordinary Marshallian demands. With proper adaptation, the entire body of estimation results derived by Willig can be carried over to the particular type of intertemporal decision problem which underlies the demands for financial instruments. Using a properly defined analogue to the usual measure of multidimensional consumer surplus, $C V$ can be expressed in terms of this observable plus an error term subject to bounds that can be calculated from observable market data.

The appropriate multidimensional surplus measure for this purpose is the sum of areas under sequentially shifted Fisherian demands for loans and deposits, when those demands take their price and future value forms. For $\tilde{\mathbf{d}}$ and $\tilde{\mathbf{p}}$ arbitrary but fixed, define depositor surplus, $D S$, and borrower surplus, $B S$, as

$$
\begin{aligned}
D S & \equiv \sum_{K=1}^{T} \int_{\mathrm{d}_{k}}^{d_{k}} D_{k}\left(d_{1}, \ldots, d_{k-1}, \xi, \tilde{d}_{k+1}, \ldots, \tilde{d}_{T}, \tilde{\mathbf{p}}, w\right) d \xi \\
B S & \equiv \sum_{k=1}^{T} \int_{p_{k}}^{\tilde{p}_{k}}-L_{k}\left(\mathbf{d}, p_{1}, \ldots, p_{k-1}, \xi, \tilde{p}_{k+1}, \ldots, \tilde{p}_{T}, w\right) d \xi
\end{aligned}
$$

and let $A \equiv D S+B S$. Here, $A$ is completely analogous to the particular form of the 


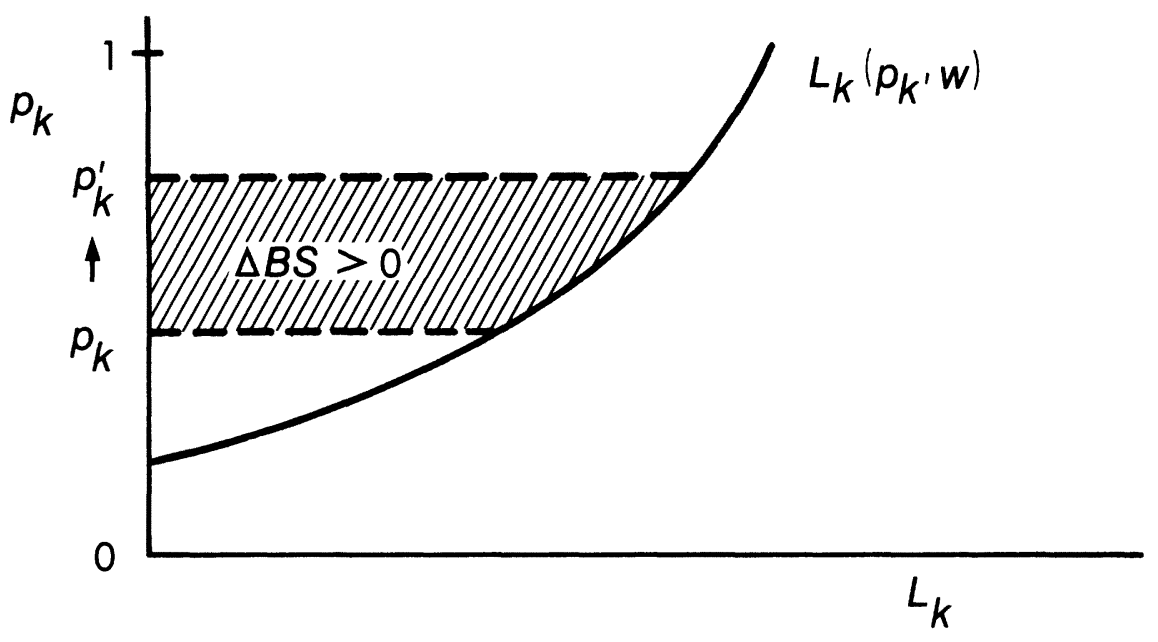

Figure 1.

multidimensional surplus measure used by Willig [11, 54], and it represents the sum of areas under sequentially shifted Fisherian demands for loans and deposits, when those demands are written as functions of loan and deposit prices. ${ }^{9}$ Letting $t \equiv C V-A$ denote the deviation of observable surplus from the compensating variation in wealth, the corollary to Proposition 1 permits the indirect utility function to be written as

$$
\tilde{v}(\mathbf{p}, \mathbf{d}, w) \equiv w+A+t .
$$

To assess the welfare effect of deposit and loan price changes, only the changes in $B S$, $D S$, and the deviation term need be known. For example, consider the case of a single loan price change. Let $p_{k}^{\prime}>p_{k}$, and define $\mathbf{p}^{\prime} \equiv\left(p_{1}, \ldots, p_{k-1}, p_{k}^{\prime}, p_{k+1}, \ldots, p_{T}\right)$. Letting $T \equiv t-t^{\prime}$ be the change in the deviation from $C V$, the change in welfare from the loan price increase from $p_{k}$ to $p_{k}^{\prime}$ reduces to

$$
\tilde{v}\left(\mathbf{p}^{\prime}, \mathbf{d}, w\right)-\tilde{v}(\mathbf{p}, \mathbf{d}, w)=\int_{p_{k}}^{p_{k}^{\prime}} L_{k}\left(\mathbf{d}, p_{1}, \ldots, p_{k-1}, \xi, p_{k+1}, \ldots, p_{T}, w\right) d \xi+T .
$$

The integral measures the (signed) change in borrower surplus. This will be positive and is illustrated in Figure 1 as the area $\Delta B S$.

In general, the results obtainable on estimating the compensating variation in wealth using borrower and depositor surplus are entirely analogous to those derived by Willig on estimating the compensating variation in income with consumer surplus. When wealth elasticities of the Fisherian loan and deposit demands are constant, $C V$ can be calculated exactly from the observable surpluses. When wealth elasticities are non-constant, upper and lower bounds on the error in using $B S$ and $D S$ to estimate $C V$ can be reliably calculated. Since Willig's results are well-known, and since all of his approximation results

9. $A$ has been defined in terms of a particular sequence of price changes, taking the deposit price changes first and then the loan price changes. Unlike $C V$ which is the sum of path-independent integrals of Hicksian demands, the value of $A$ is path-dependent and does depend on the sequence of prices chosen. The choice of different paths will not alter any of the general relationships between $A$ and $C V$ given above, but it will alter the magnitudes of $A$ and of the error term, as well as the "tightness" of the bounds calculable on that error. The particular sequence of price changes used above was chosen arbitrarily, and is neither necessary nor optimal in any sense. 
carry over to the present case when the proper specifications of borrower and depositor surplus in (12) are substituted for ordinary consumer surplus in his derivations, it will not be necessary to catalog all of those same results and their derivations here. The reader with special needs or interests in the details of these arguments is referred to Jehle [5]. For convenience, however, a few of the most useful results for the case of a single price change are reproduced here as Proposition 2, and proofs are sketched in the Appendix.

Proposition 2. Let $\eta$ denote the wealth elasticity of the relevant Fisherian demand function. For the case of a change in loan price $p_{k}, \eta$ takes the interpretation $\eta \equiv$ $\left(\partial L_{k} / \partial w\right)\left(w / L_{k}\right)$. For a change in deposit price $d_{k}, \eta \equiv\left(\partial D_{k} / \partial w\right)\left(w / D_{k}\right)$. Let $A \equiv B S+$ $D S$ as in (12), and define the ratio $a \equiv|\mathrm{A}| / w$. Then we have the following three cases of interest.

(i) Non-constant Wealth Elasticity. If wealth elasticity is non-constant over the relevant range, but $\bar{\eta} \geq \eta \geq \eta$ are upper and lower bounds on the values taken by $\eta$ in that range, then the error in estimating $C V$ with $A$ can be bounded as follows:

$\left.\left[(1+(1-\underline{\eta}) a)^{1 /(1-\underline{\eta})}-1-a\right] / a \leq T /|A| \leq\left[(1+(1-\bar{\eta}) a)^{1 /(1-\bar{\eta})}-1-a\right)\right] / a$ for $1+(1-\underline{\eta}) a>0,1+(1-\bar{\eta}) a>0$, and $\underline{\eta} \neq 1, \bar{\eta} \neq 1$.

(ii) Constant Wealth Elasticity. If $\eta$ is constant over the relevant range of wealth and price space, then CV may be calculated exactly as:

$$
\begin{aligned}
C V & =w\left[(1+(1-\eta) a)^{1 /(1-\eta)}-1\right], & & \eta \neq 1 \\
& =w[\exp (a)-1], & & \eta=1 .
\end{aligned}
$$

(iii) Rule of Thumb. When $\eta$ is constant, or when $\bar{\eta}$ and $\eta$ are not too far apart, the percentage error in using $A$ to approximate $C V$ will usually be of the following rough order of magnitude in most applications:

$$
T /|A| \approx \eta a / 2
$$

\section{Surplus Calculation Using Interest Rates}

The demand functions for loan and deposit instruments used above, from which the welfare and surplus results were derived, are defined in their price and future value forms in order to be able to make easy use of Willig's large body of approximation results. For the purpose of establishing the necessary analogies to Willig's results, this was the most straightforward approach to take. However, for most empirical applications, and for some theoretical purposes, it is usually more convenient to work with interest rates and the present value of loan or deposit contracts - the amounts actually borrowed or lent rather than with discount rates and the future value of contracts when, for example, estimating demand functions and calculating surpluses. The translation into these terms is straightforward and should provide an easier and more intuitive approach to take in many cases. It will be shown, however, that borrower and depositor surplus, the proper observable measures of individual welfare, cannot be simply interpreted as the areas under deposit and loan demand functions when those functions are written in terms of interest 
rates. The analogies between surplus measures appropriate to demands for financial instruments and those appropriate to demands for ordinary goods and services, which have been drawn by Rhoades [9] and others, are thus shown to be subject to previously unrecognized conceptual and computational errors.

The demand functions $L_{k}(\mathbf{p}, \mathbf{d}, w)$ and $D_{k}(\mathbf{p}, \mathbf{d}, w)$ are defined above as the future values, $k$ periods hence, of the loan and deposit contracts sold or brought in the current period. Prices $p_{k}=1 /\left(1+r_{k}\right)^{k}$ and $d_{k}=1 /\left(1+\delta_{k}\right)^{k}$ of these contracts are the "discount rates" which can be applied to the demand functions to obtain the present value of the contracts in the current period. For $\mathbf{r} \equiv\left(r_{1}, \ldots, r_{T}\right), \delta \equiv\left(\delta_{1}, \ldots, \delta_{T}\right)$, and writing $L_{k}^{*}$ and $D_{k}^{*}$ to indicate "present value demand functions," equations (15) give the present value of the contracts, or the volumes of funds actually received or given up in the current period, viewed as functions of interest rates.

$$
\begin{aligned}
& L_{k}^{*}(\mathbf{r}, \boldsymbol{\delta}, w) \equiv p_{k} L_{k}(\mathbf{p}, \mathbf{d}, w) \\
& D_{k}^{*}(\mathbf{r}, \boldsymbol{\delta}, w) \equiv d_{k} D_{k}(\mathbf{p}, \mathbf{d}, w)
\end{aligned}
$$

The interest rate forms are the most common ones which loan and deposit demands take in empirical and theoretical analysis. Using (15), the relationship of borrower and depositor surplus measures to the present value interest rate forms of these demand functions can be easily established.

Proposition 3. Let $L_{k}^{*}(\mathbf{r}, \boldsymbol{\delta}, w)$ give the volume of funds demanded in the current period for a term of $k$ periods at an interest rate of $r_{k}$ per-period, and let $D_{k}^{*}(\mathbf{r}, \delta w)$ give the volume of funds supplied in the current period for a term of $k$ periods at an interest yield of $\boldsymbol{\delta}_{k}$ per period. Then, for $\tilde{\mathbf{r}}$ and $\tilde{\boldsymbol{\delta}}$ arbitrary but fixed, the only observable surplus measures which bear a well-defined relationship to $C V$, the theoretically correct measure of individual welfare, are the following interest rate forms of the multi-dimensional borrower and depositor surpluses:

$$
\begin{aligned}
D S & \equiv \sum_{k=1}^{T} \int_{\tilde{\delta}_{k}}^{\delta_{k}} k\left[D_{k}^{*}\left(\delta_{1}, \ldots, \delta_{k-1}, z, \tilde{\delta}_{k+1}, \ldots, \tilde{\delta}_{T}, \tilde{\mathbf{r}}, w\right) /(1+z)\right] d z \\
B S & \equiv \sum_{k=1}^{T} \int_{r_{k}}^{\tilde{r}_{k}} k\left[L_{k}^{*}\left(\delta, r_{1}, \ldots, r_{k-1}, z, \tilde{r}_{k+1}, \ldots, \tilde{r}_{T}, w\right) /(1+z)\right] d z .
\end{aligned}
$$

Proof. The relationship of $C V$ to $D S$ and $B S$ has already been established, so it will be sufficient to show that the interest rate forms of $D S$ and $B S$ above are equivalent to the price forms in (12). The proof consists of applying a simple change of variables theorem to each of the integrals in (12) and substituting from (15). Denote the $k$ th element of $B S$ in (12) by $B S_{k}$ and recognize the $p_{k}=g\left(r_{k}\right) \equiv\left(1+r_{k}\right)^{-k}$, so that $g^{\prime}\left(r_{k}\right)=-\left(k /\left(1+r_{k}\right)\right) g\left(r_{k}\right)$. By (15), $L_{k}^{*}\left(r_{k}\right)=g\left(r_{k}\right) L_{k}\left(g\left(r_{k}\right)\right)$. Performing the change of variables and substituting gives $^{10}$

$$
B S_{k} \equiv \int_{p_{k}}^{\tilde{p}_{k}}-L_{k}(\xi) d \xi=\int_{r_{k}}^{\tilde{r}_{k}}-L_{k}(g(z)) g^{\prime}(z) d z=\int_{r_{k}}^{\tilde{r}_{k}} k\left[L_{k}^{*}(z) /(1+z)\right] d z .
$$

Summing over all $k$ establishes the claim for $B S$ in the statemet of the proposition, and an identical argument establishes the claim for $D S$. Q.E.D.

10. See any calculus text or [8] for a proof of the change of variables theorem. 


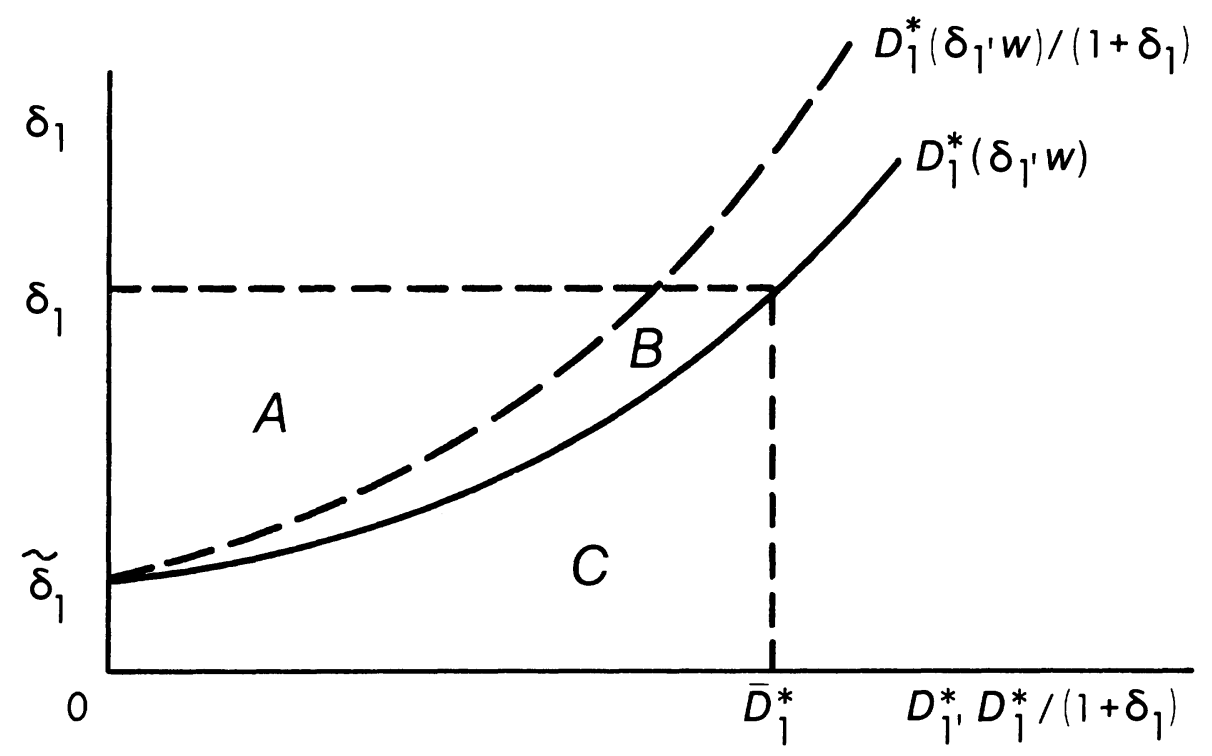

Figure 2.

Borrower and depositor surplus, calculated as in Proposition 3 from the usual interest rate forms of loan and deposit demand functions, are directly substitutable for $B S$ and $D S$ in Proposition 2. All results relating these surpluses to $C V$ and individual welfare remain unchanged when this method of calculation is used. ${ }^{11}$

It is important to notice that $D S$ and $B S$ are not simply equal to the areas between two interest rate levels underneath the interest rate forms of the observable Fisherian loan and deposit demand functions. The correct surplus measures are those areas "scaled" by the maturity of the loan or deposit in terms of the number of standard periods, $k$, and "discounted" over the range of integration by the factor $(1+z)^{-1}$. The intuition of this is perhaps clearest in the case of single-period lending represented in Figure 2.

In Figure 2, the single-period deposit rate $\delta_{1}$ is graphed against the amount of funds supplied in the current period, $D_{1}^{*}$, and the discounted transformation $D_{1}^{*} /\left(1+\delta_{1}\right)$. The area $C$ can be thought of heuristically as approximating the minimum interest income that must accrue to the depositor over the period in order to induce him to supply the amount $\bar{D}_{1}^{*}$ at the beginning of the period. The total of the areas $A, B$ and $C$ is the amount of interest income that actually does accrue to the depositor over the period. The excess of what is received over what is minimally necessary - areas $A+B$, or the simple surplus measures a sort of surplus in income that the depositor holder receives over the period. This income, however, is not paid to the individual until the end of the period. The compensating variation in wealth, on the other hand, measures the adjustment in wealth the individual requires at the beginning of the period to make him just as well off (in this case) holding no deposits as he would be holding $\bar{D}_{1}^{*}$ paying $\delta_{1}$ over the period. In effect, the area $A+B$ measures the sum of (infinitely small) incremental income surpluses which will not be paid until the end of the period. They must, therefore, be "discounted" to

11. Notice also that the wealth elasticities calculated from the future value forms $L_{k}$ and $D_{k}$ and used in the bounding process in Proposition 2 are equal to the wealth elasticities calculated directly from the interest rate forms $L_{k}^{*}$ and $D_{k}^{*}$. Taking loan demand for illustration and letting $\eta \equiv\left(\partial L_{k} / \partial w\right) /\left(w / L_{k}\right)$, it is clear from (15) that $\left(\partial L_{k}^{*} / \partial w\right) /$ $\left(w / L_{k}^{*}\right)=p_{k}\left(\partial L_{k} / \partial w\right)\left(w / p_{k} L_{k}\right)=\eta$. 
beginning-of-period values by the discount factor in Proposition 3 over the relevant range of interest rate values in order to conform with the proper ex ante measure of compensating variation. This discounted area, the proper measure of depositor surplus, is equal to the area $A$ and will always be less than the simple surplus area $A+B$ in the single-period case. A similar interpretation holds for the case of borrower surplus.

It should be emphasized that casual use of simple areas under loan and deposit demand functions to estimate welfare effects of interest rate changes can lead to serious errors and result in spurious welfare inferences. It is easily shown that such simple calculations will sometimes overestimate and sometimes underestimate the proper $B S$ and $D S$ measures, depending on the term of the loan or deposit and the upper and lower interest rate levels over the range of integration. For the commonly applied special case of single period borrowing or lending, however, the simple surplus calculation will always overestimate the proper $B S$ and $D S$ measures, as Figure 2 reveals. Proposition 4 gives a convenient characterization of the general relationship between interest rate levels, term, and the extent of the error made when using simple surpluses, instead of borrower or depositor surplus, for arbitrary loan and deposit demand functions.

Proposition 4. Define the simple surplus under the demand curve for a loan of maturity $k$ as

$$
S S \equiv \int_{r^{0}}^{r^{\prime}} L^{*}(z) d z
$$

and the simple surplus under the demand for deposits of maturity $k$ as

$$
\bar{S} \bar{S} \equiv \int_{\delta^{0}}^{\delta^{\prime}} D^{*}(z) d z .
$$

Define the errors $E \equiv B S-S S$ and $\bar{E} \equiv D S-\bar{S} \bar{S}$.

(i) If $r^{\prime}>r^{0}$, then $k /\left(1+r^{\prime}\right)-1 \leq E /|S S| \leq k /\left(1+r^{0}\right)-1$.

(ii) If $\delta^{\prime}>\delta^{0}$, then $k /\left(1+\delta^{\prime}\right)-1 \geq \bar{E} /|\bar{S} \bar{S}| \geq k /\left(1+\delta^{0}\right)-1$.

Proof. (Only (i) will be proven since the proof for (ii) is identical.) Notice that the error $E$ can be written as the integral of the product of two functions

$$
E=\int_{r^{0}}^{r^{\prime}} L^{*}(z)(k /(1+z)-1) d z
$$

where $L^{*}(z) \geq 0$ and $k /\left(1+r^{\prime}\right)-1 \leq k /(1+z)-1 \leq k /\left(1+r^{0}\right)-1$ for $r^{0} \leq z \leq$ $r^{\prime}$. Integrals of the product of two such functions can be bounded as follows $[8,553]$ :

$\left(k /\left(1+r^{\prime}\right)-1\right) \int_{r^{0}}^{r^{\prime}} L^{*}(z) d z \leq \int_{r^{0}}^{r^{\prime}} L^{*}(z)(k /(1+z)-1) d z \leq\left(k /\left(1+r^{0}\right)-1\right) \int_{r^{0}}^{r^{\prime}} L^{*}(z) d z$.

Substituting $B S$ and $D S$ from Proposition 3, $S S$ from the definitions above and rearranging establishes the claim. Q.E.D.

Taking the case of loan demand and borrower surplus as an example, some illustrative calculations based on Proposition 4 are presented in Table I. The entries in each of the last 
Table I. Minimum Deviation $E=B S-\mathrm{SS}$ as a Proportion of $S S$

\begin{tabular}{cccccc}
\hline & & & & \multicolumn{3}{c}{$E /|S S| \geq$} \\
\cline { 4 - 6 }$r^{\circ}$ & $\begin{array}{c}\text { Increase } \\
\left(\% \text { of } r^{\circ}\right)\end{array}$ & $r^{\prime}$ & $k=1$ & $k=2$ & $k=5$ \\
\hline \multirow{2}{*}{.05} & $1 \%$ & .0505 & -.048 & .904 & 3.760 \\
& $5 \%$ & .0525 & -.050 & .901 & 3.751 \\
& $10 \%$ & .0550 & -.052 & .896 & 3.739 \\
& $20 \%$ & .0600 & -.057 & .887 & 3.717 \\
.10 & $1 \%$ & .1010 & -.092 & .817 & 3.541 \\
& $5 \%$ & .1050 & -.095 & .810 & 3.525 \\
& $10 \%$ & .1100 & -.099 & .802 & 3.505 \\
.15 & $1 \%$ & .1515 & -.132 & .737 & 3.342 \\
& $5 \%$ & .1575 & -.136 & .728 & 3.320 \\
& $10 \%$ & .1650 & -.142 & .717 & 3.292 \\
\hline
\end{tabular}

three columns of the table give the minimum error as a proportion of the simple surplus area $(E /|S S|)$ for loan rate increases ranging from $1 \%$ to $20 \%$ of various base interest rate levels between .05 and .20 , for loans of a given maturity, $k$. These calculations show quite clearly how unreliable the simple surplus areas are as indicators of the welfare effects of interest rate changes. If the observed demand function is for a loan instrument with a term of one period, Proposition 4 shows that the simple surplus will always over-estimate the welfare effect of an interest rate change and, for the examples given in Table I, that overestimate may range from as little as $4.8 \%$ to as much as $14.2 \%$ of the calculated surplus, depending on the base interest rate and the extent of the rate change. If, however, the observed loan demand function is for a loan instrument with a maturity of at least two periods then, in the examples given, the simple surplus will often under-estimate the true welfare effect of the rate change to the extent of several hundred percent of the calculated surplus. These are errors which must be considered important in any serious attempt at the measurement of the welfare incidence of interest rate changes.

\section{Welfare Costs of Bank Mergers}

This section will briefly describe how the welfare methods just presented can be applied in practice to contribute to the design of rational and equitable public policy towards bank mergers. Bank merger policy is an important area of concern to agencies such as the FDIC, the Federal Reserve, and the Justice Department, which are responsible for regulating the banking industry. The results obtained below challenge the conventional wisdom among bank regulators that mergers which cause large changes in concentration are prima facie socially undesirable.

The qualitative aspects of bank mergers are well-known in the literature. Standard Chamberlinian analysis of the relationship between market structure, firm conduct, and market "performance" in monopolistically competitive banking markets suggests that bank 
mergers, insofar as they lead to increased banking concentration, can be expected to result in higher market loan rates and lower market deposit rates. Many empirical studies have tested this basic hypothesis and have estimated the relationship between loan and deposit rate levels and measures of market concentration. ${ }^{12}$ While such calculations abound in the literature, for illustrative purposes here the results of Heggestad and Mingo [2] can be taken to represent a reasonable consensus in this literature. They estimate that an increase of 1.98 basis points in the loan rate and a decrease of .27 basis points in the deposit rate can be anticipated for every 100 basis points increase in the Herfindhal, $H=\Sigma s_{i}^{2}$, where $0 \leq s_{i} \leq 1$ is the market share of bank $i$, and the index runs over all banks in the relevant market. A merger between banks $i$ and $j$, having market shares $s_{i}$ and $s_{j}$, will cause a change in the Herfindhal of $\Delta H=2 s_{i} s_{j}>0$. If the pre-merger market interest rates are $r^{0}$ and $\delta^{0}$, then the expected post-merger interest rates will be $r^{\prime}=r^{0}+(1.98)\left(2 s_{i} s_{j}\right)>r^{0}$ and $\delta^{\prime}=\delta^{0}-.27\left(2 s_{i} s_{j}\right)<\delta^{0}$. The larger the market shares of the merging banks, therefore, the larger the change in concentration with merger and the larger the change in interest rates expected. It is therefore generally believed that a merger which "significantly" increases concentation will tend to have "significantly" adverse effects on borrowers and depositors.

To apply such rules of thumb based on market shares and changes in concentration when evaluating merger proposals is subject to a number of a priori objections. For one, a merger causing a given change in concentration and a given change in interest rates should be expected to have very different effects on welfare depending on the depth and elasticity of demand in the relevant market, as well as on the absolute level of interest rates prevailing at the time of the merger. Simple market-share rules fail to capture these important influences.

Building on the results of the Structure-Performance (SP) literature, borrower and depositor surplus techniques can be used to calculate dollar-figure estimates of the welfare losses likely to be suffered by borrowers and depositors as a result of a particular bank merger in a given market. The method is straightforward. First, estimates of the relevant market-level loan and deposit demand functions can be made from historical data on market interest rates, income, and other economic and demographic data. Then, the expected interest rate changes can be calculated using the estimated relationships between interest rate levels and measures of market concentration from the SP literature. The welfare costs to borrowers and depositors can then be approximated by the changes in borrower and depositor surplus.

Elsewhere, this technique has been used to calculate borrower and depositor welfare losses in a sample of 28 merger cases considered by the FDIC over the period 1970-79. Assuming for simplicity that all loans and deposits had a term of one period, pooled cross-section and time series data were used to estimate representative per-capita demands for loans and deposits. The 28 market-level demands were then obtained by evaluating these estimated functions at the values of the independent variables obtaining in each market at the time of the proposed merger. ${ }^{13}$

12. See Rhoades [9] for an excellent survey of this literature.

13. The estimated demand equations are

$$
\begin{aligned}
& \log \left(L^{*}\right)=3.67-.857 \log (L I R)+1.09 \log (I N C)+.225 \log (U R), \quad R^{2}=.68 \\
& \text { (5.11) (-2.10) (4.68) (2.97) }
\end{aligned}
$$


The market shares of the merging banks in the sample produced changes in market concentration measured by the Herfindhal ranging from 2 to 1,106 basis points. Estimates of the post-merger interest rate levels were calculated as described earlier using the results of Heggestad and Mingo, and estimates of the welfare costs of the mergers in the sample were computed using Proposition 3 . Welfare costs varied considerably over the mergers in the sample, and these calculations are reported in Table II. In all cases, borrower and depositor surplus changes provided accurate estimates of the welfare effects of the mergers on borrowers and depositors. Using the bounding procedure in Proposition 2, it was found that the errors made in using the observable surplus measures to approximate the true welfare changes were negligible, and in no case exceeded a few tenths of one percent of the calculated surplus. Per-capita borrower surplus losses ranged from $\$ .01$ to $\$ 23.33$, and per-capita depositor surplus losses ranged from $\$ .002$ to $\$ 4.67$. The mergers in the sample gave rise to a mean cost of $\$ .89$ per-capita for depositors and $\$ 5.61$ per-capita for borrowers.

A simple $F$-test was applied to the data in Table II to test the null hypotheses that there is no correlation between changes in borrower surplus and changes in concentration, and no correlation between changes in depositor surplus and changes in concentration. The calculated $F$-statistics in the two cases were .138 and .388 , respectively, Both are less than the critical value of 1.38 , and so the null hypotheses that there is no correlation between changes in concentration and changes in either borrower or depositor welfare cannot be rejected at the $25 \%$ significance level.

While rough and imperfect in ways, these simple calculations are nonetheless suggestive. They cast doubt on the conventional wisdom relating market shares and changes in concentration to the expected welfare losses from bank mergers, and they direct attention to the importance of the market interest rate level and the depth and elasticity of demand in determining the welfare impact of particular mergers in particular markets. The importance of these factors illustrates the advantages of borrower and depositor surplus methods over traditional methods of merger analysis. First, they provide observable and accurate indices of welfare change which bear a well-defined relation to accepted theoretical measures of welfare. Second, they provide a means of gauging welfare costs which is sensitive to market-specific characteristics of the particular banking market being considered. Finally, by providing dollar estimates of the welfare costs of mergers to depositors and to borrowers, these techniques permit a more careful weighing of the costs of a merger against its benefits, and they help give policy-makers greater insight into the distributional consequences of their decisions.

\section{Conclusion}

Building from a standard Fisherian intertemporal consumption model, this paper has shown how exact measures of the relationship between individual welfare and discount

$$
D^{*}=\underset{(.987)}{2.85}+\underset{(2.60)}{135.41 D I R}+\underset{(2.64)}{186.75 I N C,} R^{2}=.73 .
$$

Numbers in parentheses are $t$-statistics, $L I R$ is the loan interest rate, $D I R$ the deposit interest rate, $I N C$ is per-capita income, $U R$ is the unemployment rate. See [5] for a complete description of the data and methods used in the estimation and surplus calculations. 
Table II. Per-Capita Welfare Loss in 28 FDIC Bank Merger Cases, 1970-79

\begin{tabular}{|c|c|c|c|}
\hline Market & $\Delta H^{*}$ & $\Delta B S$ & $\Delta D S$ \\
\hline 1 & 0.454 & 1.20 & 0.200 \\
\hline 2 & 0.238 & 1.04 & 0.130 \\
\hline 3 & 0.277 & 3.23 & 0.760 \\
\hline 4 & 1.829 & 5.76 & 1.460 \\
\hline 5 & 3.276 & 1.30 & 0.190 \\
\hline 6 & 0.390 & 9.65 & 1.860 \\
\hline 7 & 3.640 & 5.15 & 0.710 \\
\hline 8 & 1.667 & 0.42 & 0.060 \\
\hline 9 & 5.263 & 13.10 & 2.290 \\
\hline 10 & 0.130 & 6.70 & 0.920 \\
\hline 11 & 2.122 & 10.43 & 1.710 \\
\hline 12 & 4.424 & 6.30 & 1.080 \\
\hline 13 & 2.563 & 7.26 & 1.010 \\
\hline 14 & 2.400 & 20.74 & 0.820 \\
\hline 15 & 2.088 & 3.44 & 0.600 \\
\hline 16 & 4.558 & 2.42 & 0.370 \\
\hline 17 & 1.315 & 10.80 & 1.680 \\
\hline 18 & 0.762 & 6.82 & 1.000 \\
\hline 19 & 3.360 & 0.07 & 0.010 \\
\hline 20 & 0.554 & 23.33 & 4.670 \\
\hline 21 & 2.318 & 0.17 & 0.030 \\
\hline 22 & 0.020 & 2.49 & 0.510 \\
\hline 23 & 0.432 & 1.59 & 0.310 \\
\hline 24 & 11.060 & 1.33 & 0.220 \\
\hline 25 & 0.075 & 0.24 & 0.040 \\
\hline 26 & 1.240 & 0.03 & 0.002 \\
\hline 27 & 0.794 & 0.01 & 0.002 \\
\hline 28 & 0.543 & 15.76 & 3.150 \\
\hline
\end{tabular}

${ }^{*}$ Hundreds of basis points.

rates or interest rates on financial instruments can be constructed. It was shown that, with proper adaptation and proper accounting for the role of time in the decision to borrow or lend, methods identical to those of Willig can be applied to measure the welfare effects of interest rate changes with a high degree of accuracy, using observable market data.

For the purpose of social welfare analysis, it is a straightforward matter to construct flexible Bergsonian social welfare functions from the individual's indirect utility function given in the corollary to Proposition 1, or in (13), with no more than the usual difficulties encountered in aggregation. Adopting the social welfare function approach to such problems as banking market structure analysis, in conjunction with the approximation and 
computational results in Propositions 2 and 3, enables the analyst to make empirical measurements of the costs and benefits of different policies, to weigh them against each other, and to arrive at a net social decision which has an unambiguous welfare theoretic justification. $^{14}$

An important question which has not been addressed here, but which bears further careful research, is the extent to which the theoretical and computational results derived in the Fisherian case of perfect certainty apply in a model of individual demands for financial instruments which emphasizes the role of uncertainty. see [5].

14. For a fuller treatment of these issues in general, and in the kind of spatial market analysis typical in banking,

\section{Appendix}

The purpose of this appendix is to prove Proposition 2 and to give more detail to the precise relationship between observable measures of depositor and borrower surplus and the compensating variation in wealth. All results and methods of derivation follow exactly, by analogy, those of Willig $[11 ; 12]$. No effort is made to reproduce the considerable body of approximation results reported by Willig. Instead, the purpose here is to sketch the basic argument and to acquaint the reader having more specific needs with the modifications which will be necessary to interpret Willig's results in the context of demands for financial instruments. Terms have been defined consistently so that the reader may refer directly to Willig's larger body of results, without the need to translate notation. Finally, for simplicity in the exposition here, only the case of single price changes for an individual will be treated. Proofs and more extended arguments for cases of multiple price changes and aggregation are provided in [5].

Consider first the effect on individual welfare of a single loan-price change from $p_{k}^{0}$ to $p_{k}^{\prime}$ for instrument $L_{k}\left(\mathbf{p}, \mathbf{d}, w^{0}\right)$ given base wealth $w^{0}$. Let $\mathbf{p}^{0} \equiv\left(p_{1}^{0}, \ldots, p_{T}^{0}\right)$ and $\mathbf{p}^{\prime} \equiv\left(p_{1}^{0}, \ldots, p_{k}^{\prime}, \ldots, p_{T}^{0}\right)$. Define $C V$ and $A$ as in (11) and (12). Let $\underline{\eta}$ and $\bar{\eta}$ be lower and upper bounds, respectively, on the wealth elasticity of loan demand, $\left(\partial L_{k} / \partial \bar{w}\right)\left(w / L_{k}\right)$, over the relevant region of price-wealth space. Finally, notice that for any $w_{2} \geq w_{1}$, the Mean Value Theorem gives,

$$
\left[w_{2} / w_{1}\right]^{\eta} \leq L_{k}\left(p, w_{2}\right) / L_{k}\left(p, w_{1}\right) \leq\left[w_{2} / w_{1}\right]^{\bar{\eta}} .
$$

For the case of a loan-price decrease (loan interest rate increase), $p_{k}{ }^{\prime}<p_{k}^{0}$, so by (10) and (12), $\mu\left(\mathbf{p}^{\prime} \mid \mathbf{p}^{0}, w^{0}\right)>\mu\left(\mathbf{p}^{0} \mid \mathbf{p}^{0}, w^{0}\right)=w^{0}$ and

$$
\begin{aligned}
& C V=\mu\left(\mathbf{p}^{\prime} \mid \mathbf{p}^{0}, w^{0}\right)-\mu\left(\mathbf{p}^{0} \mid \mathbf{p}^{0}, w^{0}\right)>0 \\
& A=B S=\int_{p_{k}^{0}}^{p_{k}^{\prime}} L_{k}\left(p_{1}^{0}, \ldots, p_{k-1}^{0}, \xi, p_{k+1}^{0}, \ldots, p_{T}^{0}, w^{0}\right) d \xi>0 .
\end{aligned}
$$

For $\left\{\mathbf{p} \mid \mathbf{p}=t \mathbf{p}^{0}+(1-t) \mathbf{p}^{\prime} ; 0 \leq t \leq 1\right\}$, letting $w_{2}=\mu\left(\mathbf{p} \mid \mathbf{p}^{0}, w^{0}\right) \equiv \mu(\mathbf{p})$ and $w_{1}=\mu\left(\mathbf{p}^{0}\right)=w^{0},(\mathrm{~A} 1)$ gives

$$
\left[\mu(\mathbf{p}) / w^{0}\right)^{\eta} \leq L_{k}(\mathbf{p}, \mu(\mathbf{p})) / L_{k}\left(\mathbf{p}, w^{0}\right) \leq\left(\mu(\mathbf{p}) / w^{0}\right)^{\bar{\eta}} .
$$

Rearrangement and substitution of $-\partial \mu / \partial p_{k}$ for $L_{k}(\mathbf{p}, \mu(\mathbf{p}))$ by (10) gives

$$
w^{o^{-} \underline{\eta}} \cdot L_{k}\left(\mathbf{p}, w^{0}\right) \leq-\left(\partial / \partial p_{k}\right)\left[\mu(\mathbf{p})^{1-\eta} /(1-\underline{\eta})\right] \text { and, }
$$




$$
-\left(\partial / \partial p_{k}\right)\left[\mu(\mathbf{p})^{1-\bar{\eta}} /(1-\bar{\eta})\right] \leq w^{o^{-\bar{\eta}}} \cdot L_{k}\left(\mathbf{p}, w^{0}\right) .
$$

Integrating both sides of these two inequalities from $p_{k}^{\prime}$ to $p_{k}^{0}$ preserves the inequalities. Rearranging terms gives,

$$
\left.w^{0}\left[1+(1-\underline{\eta}) A / w^{0}\right]^{1 /(1-\eta}\right) \leq \mu\left(\mathbf{p}^{\prime}\right) \leq w^{0}\left[1+(1-\bar{\eta}) A / w^{0}\right]^{1 /(1-\bar{\eta})}
$$

for $1+(1-\underline{\eta}) A / w^{0}>0$ and $1+(1-\bar{\eta}) A / w^{0}>0$; and $\bar{\eta} \neq 1, \underline{\eta} \neq 1$.

For $T \equiv C V-A$, and given (A2), the error incurred in using $A$ instead of $C V$ measured as a proportion of the absolute value of the surplus, $T /|A|$, is obtained directly from (A4). Letting $a \equiv$ $|A| / w^{0}$, the bounds on this error may be written

$$
\left[(1+(1-\underline{\eta}) a)^{1 /(1-\eta)}-1-a\right] / a \leq T /|A| \leq\left[(1+(1-\bar{\eta}) a)^{1 /(1-\bar{\eta})}-1-a\right] / a
$$

which establishes the claim in Proposition 2(i).

The case of a deposit-price increase (deposit interest rate decrease) can be treated similarly. For $\mathbf{d}^{\prime} \equiv\left(d_{1}^{0}, \ldots, d_{k}^{\prime}, \ldots, d_{T}^{0}\right)$ and $\mathbf{d}^{0} \equiv\left(d_{1}^{0}, \ldots, d_{k}^{0}, \ldots, d_{T}^{0}\right)$, where $d_{k}^{\prime}>d_{k}^{0}$, by (10) $\partial \mu / \partial d_{k}>0$ so $\mu\left(\mathbf{d}^{1} \mid \mathbf{d}^{0}, w^{0}\right)>\mu\left(\mathbf{d}^{0} \mid \mathbf{d}^{0}, w^{0}\right)=w^{0}$. Letting $\mu\left(\mathbf{d}^{\prime} \mid \mathbf{d}^{0}, w^{0}\right)=w_{2}$ and $\mu\left(\mathbf{d}^{0} \mid \mathbf{d}^{0}, w^{0}\right)=w_{1}$, using (A1) gives (A4) and (A5) again, where

$$
A=D S=\int_{d_{k}^{0}}^{d_{k}^{\prime}} D_{k}\left(d_{1}^{0}, \ldots, d_{k-1}^{0}, \xi, d_{k+1}^{\prime}, \ldots, d_{T}^{\prime}, w^{0}\right) d \xi>0 .
$$

Consideration of loan-price increases (loan interest rate decreases) from $\mathbf{p}^{o}$ to $\mathbf{p}^{\prime}$, and depositprice decreases (deposit interest rate increases) from $\mathbf{d}^{0}$ to $\mathbf{d}^{\prime}$, lead, by a parallel derivation, to (A4) and (A5) also. However, in these cases, (12) shows that $B S, D S$ and $A$ will be negative.

In the limit, as $\underline{\eta}$ approaches $\bar{\eta}$, (A4) shows that the compensating variation in wealth may be expressed exactly as a function of the surplus $A$. When $\bar{\eta}=\underline{\eta}=\eta \neq 1$ is constant over the relevant range, (A4) gives

$$
\mu\left(\mathbf{p}^{\prime} \mid \mathbf{p}^{0}, \mathbf{d}^{0}, w^{0}\right)=w^{0}\left[1+(1-\eta) A / w^{0}\right]^{1 /(1-\eta)}
$$

and since $\mu\left(\mathbf{p}^{0} \mid \mathbf{p}^{0}, w^{0}\right)=w^{0}$, by (A2)

$$
\mathrm{CV} \mathrm{w}^{0}\left(\left[1+(1-\eta) A / w^{0}\right]^{1 /(1-\eta)}-1\right),
$$

which proves Proposition 2(ii).

This exact relationship between the compensating variation and the observable surpluses when the wealth elasticity is constant gives rise to the final approximation result, Proposition 2 (iii), which is simpler and which may be useful when $\eta$ is constant or when $\bar{\eta}$ and $\eta$ are not too far apart. The proof consists of applying the Taylor approximation $(1+t)^{1 /(1-\eta)} \approx 1+t /(1-\eta)+\eta t^{2} / 2(1-\eta)^{2}$ to (A6) and rearranging to obtain

$$
T /|A| \approx \eta a / 2 \text {. }
$$

Willig [12] has compiled a table of numerical values for the bounds on $T$ as a percent of $A$ as given in Proposition 2(i) and (iii). Notation has been defined so that the reader may refer directly to those calculations.

\section{References}

1. Benston, G. J., "Savings Banking and the Public Interest." Journal of Money, Credit and Banking, Part II, February 1972, 133-226.

2. Heggestad, A. A. and J. J. Mingo, "Prices, Nonprices, and Concentration in Commercial Banking." Journal of Money, Credit, and Banking, February 1976, 107-17. 
3. Hicks, J. R. Value and Capital, 2nd ed. Oxford: Clarendon Press, 1946.

4. Hurwicz, L. and H. Uzawa. "On the Integrability of Demand Functions," in Preferences Utility and Demand, edited by Chipman, et al. New York: Harcourt Brace Jovanovich, 1971, pp. 114-48. 1983.

5. Jehle, G. A. "Welfare Analysis of Regulatory Policies in Banking." Ph.D. dissertation, Princeton University,

6. Morishima, M. The Theory of Demand: Real and Monetary. Oxford: Oxford University Press, 1973.

7. Policano, A. J., "Banking Structure Regulation: A Location Theory Approach." The Journal of Economics, 1977.

8. Rektorys, K., ed. Survey of Applicable Mathematics. London: Iliffe Books, 1969.

9. Rhoades, S. A., "Welfare Loss, Redistribution Effect, and Restriction of Output Due to Monopoly in Banking." Journal of Monetary Economics, May 1982, 375-87.

10. __ "Structure-Performance Studies in Banking: A Summary and Evaluation." Staff Economic Studies, U. S. Board of Governors of the Federal Reserve, 1977.

11. Willig, R. D. Welfare Analysis of Policies Affecting Prices and Products. New York: Garland Publishing, 1979.

12. ___ "Consumer Surplus Without Apology." American Economic Review, September 1976, 589-97. 